\title{
Morphology of testicular and post-testicular spermatozoa in Microstigmus arlei Richards, 1972 and M. nigrophthalmus Melo, 1992 (Hymenoptera: Apoidea: Pemphredoninae) with phylogenetic consideration
}

\author{
Uyrá Zama ${ }^{\text {acc }}$, Jane Moreira ${ }^{\mathrm{b}}$, Sônia Nair Báo ${ }^{\mathrm{a}}$, Lucio Antonio de Oliveira Campos ${ }^{\mathrm{b}}$, \\ Heidi Dolder ${ }^{\mathrm{c}}$, José Lino-Neto ${ }^{\mathrm{b}, *}$ \\ ${ }^{a}$ Departamento de Biologia Celular, Universidade de Brasília (UnB), Brasília, DF, Brazil \\ ${ }^{\mathrm{b}}$ Departamento de Biologia Geral, Universidade Federal de Viçosa (UFV), 36571000 Viçosa, MG, Brazil \\ ${ }^{\mathrm{c}}$ Departamento de Biologia Celular, Universidade Estadual de Campinas (UNICAMP), Campinas, SP, Brazil
}

Received 23 June 2006; accepted 9 November 2006

\begin{abstract}
The sperm of Microstigmus arlei and Microstigmus nigrophthalmus are twisted in a spiral and consist of two regions: the head, formed by an acrosome and a nucleus, and the flagellum, formed by two asymmetric mitochondrial derivatives, a long centriolar adjunct, an axoneme $(9+9+2)$ and two accessory bodies. The head shows a characteristic morphology. The acrosome is very long and is basically made up of a paracrystalline structure. In the central head region, the acrosome is inserted into the nucleus, which is observed coiling laterally around the paracrystalline structure. In the subsequent part of the spermatozoon the nucleus appears round in transverse sections, and over some length it is still penetrated by the acrosome until shortly distal to the flagellar insertion. At this point the nucleus forms an inverted cone-shaped projection. These morphological characteristics of acrosome and nucleus of the Microstigmus wasp have not been previously described in Apoidea and are useful for phylogenetic evaluation of this superfamily.
\end{abstract}

(C) 2007 Elsevier Ltd. All rights reserved.

Keywords: Ultrastructure; Sperm; Sphecidae; Crabronidae; Phylogeny

\section{Introduction}

The sphecids are a large and diverse group of predatory wasps. In the revision of Bohart and Menke (1976) all of them were included in a single family, Sphecidae, subdivided into 11 subfamilies. More recently, Melo (1999) recommended the recognition of four sphecid families; the Heterogydae, Ampulicidae, Sphecidae sensu stricto, and Crabronidae, which, together with the Apidae sensu lato (including all

\footnotetext{
* Corresponding author. Tel.: +55 313899 3360; fax: +55 3138992549 .

E-mail address: linoneto@ufv.br (J. Lino-Neto).
}

bee families), represent the Apoidea. He also proposed five subfamilies for the Crabronidae: Astatinae, Bembicinae, Crabroninae, Pemphredoninae, and Philanthinae. According to this classification, the genus Microstigmus is a representative of the Crabronidae, subfamily Pemphredoninae.

The genus Microstigmus Ducke (1907) includes 29 species of small wasps (about 2-4 mm), whose females prey on Collembola, Homoptera, Cicadellidae and Thysanoptera to feed their larvae (Asís, 2003). It is a peculiar genus because it is the only example of Crabronidae in which unquestionable evidence of eusociality has been found (Matthews, 1968, 1991; Ross and Matthews, 1989; Melo, 2000; Asís, 2003). For most of the species of this genus, the nests are, at least 
temporarily, occupied by more than one adult female and males (Matthews, 1991; Melo, 2000; Asís, 2003). Also, the resident females cooperate in the provisioning, cleaning, and defense of the nest (Asís, 2003). In some species, all the material necessary for nest construction is collected prior to beginning this work (Matthews and Starr, 1984), however, in other cases, they are expanded in size and shape as they harbor more occupants (Asís, 2003). Additionally, an important difference in their colony composition in relation to other social Hymenoptera is the presence of males as permanent nest residents. Nests shared by some adults (males and females) are also reported for a few Pemphredoninae, Philanthinae, and Crabroninae where this grouping can be considered as a primitive social level (Melo, 2000). The appearance of eusociality in Microstigmus is independent of its acquisition by other groups of Apoidea (Wilson, 1971; Ross and Matthews, 1989; Asís, 2003).

Besides the studies of higher Apoidea phylogeny based on traditional morphological data made by Alexander (1992) and Melo (1999), there is still very little information about the relationships amongst sphecid subgroups. Structural analyses permit a few conclusions, but many aspects of their phylogenetic relationships still remain unclear. We propose that the description of new morphological characteristics, such as obtained from sperm ultrastructure, in addition to traditional ones, will contribute toward phylogenetic studies and, eventually, lead to a stable classification of the Apoidea and their evolution.

\section{Material and methods}

Adult males of Microstigmus arlei were collected at the campus of the Federal University of Viçosa, and males of Microstigmus nigrophthalmus were collected in areas of forest fragments that surround the city of Viçosa, MG, Brazil.

\subsection{Light microscopy}

For histological investigation, the testicles and seminal vesicles of young and mature adult males were dissected and fixed for $24 \mathrm{~h}$ at $4{ }^{\circ} \mathrm{C}$ in a solution containing $4 \%$ paraformaldehyde in a $0.1 \mathrm{M}$ sodium phosphate buffer, $\mathrm{pH}$ 7.2. Dehydration was carried out in ethanol and embedding in GMA (Leica). Semithin sections were stained with hematoxylin/eosin.

For sperm measurements, seminal vesicles were dissected and broken open on clean glass microscope slides, where the sperm was spread and fixed in a solution of $4 \%$ paraformaldehyde in $0.1 \mathrm{M}$ phosphate buffer, $\mathrm{pH}$ 7.2. After drying at room temperature, the preparations were observed using phase contrast microscopy.

To measure the nucleus, some of these preparations were stained for $15 \mathrm{~min}$ with $0.2 \mu \mathrm{g} / \mathrm{ml}$ 4,6-diamino-2-phenylindole (DAPI) in phosphate buffered saline, washed and mounted with Vectashield. They were examined with an epifluorescence microscope (Olympus, BX60), equipped with a BP360-370 nm excitation filter.

For sperm measurement, the software "Image Pro-Plus" was used.

\subsection{Transmission electron microscopy}

Testes and seminal vesicles were dissected and fixed for $3 \mathrm{~h}$ in a solution containing $2.5 \%$ glutaraldehyde, $0.2 \%$ picric acid, $3 \%$ sucrose and $5 \mathrm{mM} \mathrm{CaCl}_{2}$ in $0.1 \mathrm{M}$ sodium cacodylate buffer, $\mathrm{pH}$ 7.2. The materials were postfixed in $1 \%$ osmium tetroxide, in the same buffer, for $1-2 \mathrm{~h}$. Dehydration was carried out in acetone and embedding in Epon. Ultrathin sections were stained with uranyl acetate and lead citrate and observed with the Zeiss LEO 906 and JEOL 1011 transmission electron microscopes.

For basic protein detection, the ethanolic phosphotungstic acid method (E-PTA) was applied. Seminal vesicles were fixed only in buffered glutaraldehyde solution for $24 \mathrm{~h}$ at $4{ }^{\circ} \mathrm{C}$. After washing in sodium cacodylate buffer and dehydrating in alcohol, the material was treated en bloc with a solution of $2 \%$ PTA in absolute ethanol for $2 \mathrm{~h}$ at room temperature and embedded in Epon 812.

\subsection{Phylogenetic analysis}

The cladogram was derived from trees previously published by Alexander (1992) and Melo (1999, 2005, personal communication), with the spermatozoal characters superimposed (see Table 1).

The sperm information of hymenopteran families (Vespidae, Sphecidae, Crabronidae and Apidae sensu lato) was obtained from published data and personal observations.

Table 1

List of non-polarized character states

128 spermatozoa per testicular cyst.

$1^{\prime} \quad 64$ spermatozoa per testicular cyst.

$1^{\prime \prime} \quad 32$ spermatozoa per testicular cyst.

2 Linear spermatozoa.

$2^{\prime} \quad$ Twisted spermatozoa.

3 Axonemal microtubules stain positively by E-PTA.

$3^{\prime} \quad$ Axonemal microtubules stain negatively and intertubular material stains positively by E-PTA.

4 Paracrystalline material present only in the larger mitochondrial derivative.

$4^{\prime} \quad$ Paracrystalline materials present in the both mitochondrial derivatives.

Asymmetric centriolar adjunct.

Symmetric centriolar adjunct.

Spermatozoa vary from 80 to $300 \mu \mathrm{m}$ total length.

Spermatozoa measure about $800 \mu \mathrm{m}$ of total length.

Acrosome is formed by an acrosomal vesicle covering a perforatorium (bilayered pattern).

$7^{\prime} \quad$ Acrosome is formed by a paracrystalline perforatorium without a detectable acrosomal vesicle.

8 The perforatorium is reduced in length, about $1-3 \mu \mathrm{m}$, and is than $0.05 \mu \mathrm{m}$ in diameter.

The perforatorium is the most prominent structure of head. The nucleus does not superimpose the acrosome.

The nucleus projects anteriorly, apposing the acrosome for much of its length.

10 The large mitochondrial derivative varies from oval- to pear-shaped.

$10^{\prime} \quad$ Both mitochondrial derivatives are circular in cross section.

11 The mitochondrial derivatives are markedly asymmetric in cross section.

$11^{\prime} \quad$ The mitochondrial derivatives are approximately symmetric in cross sections. 

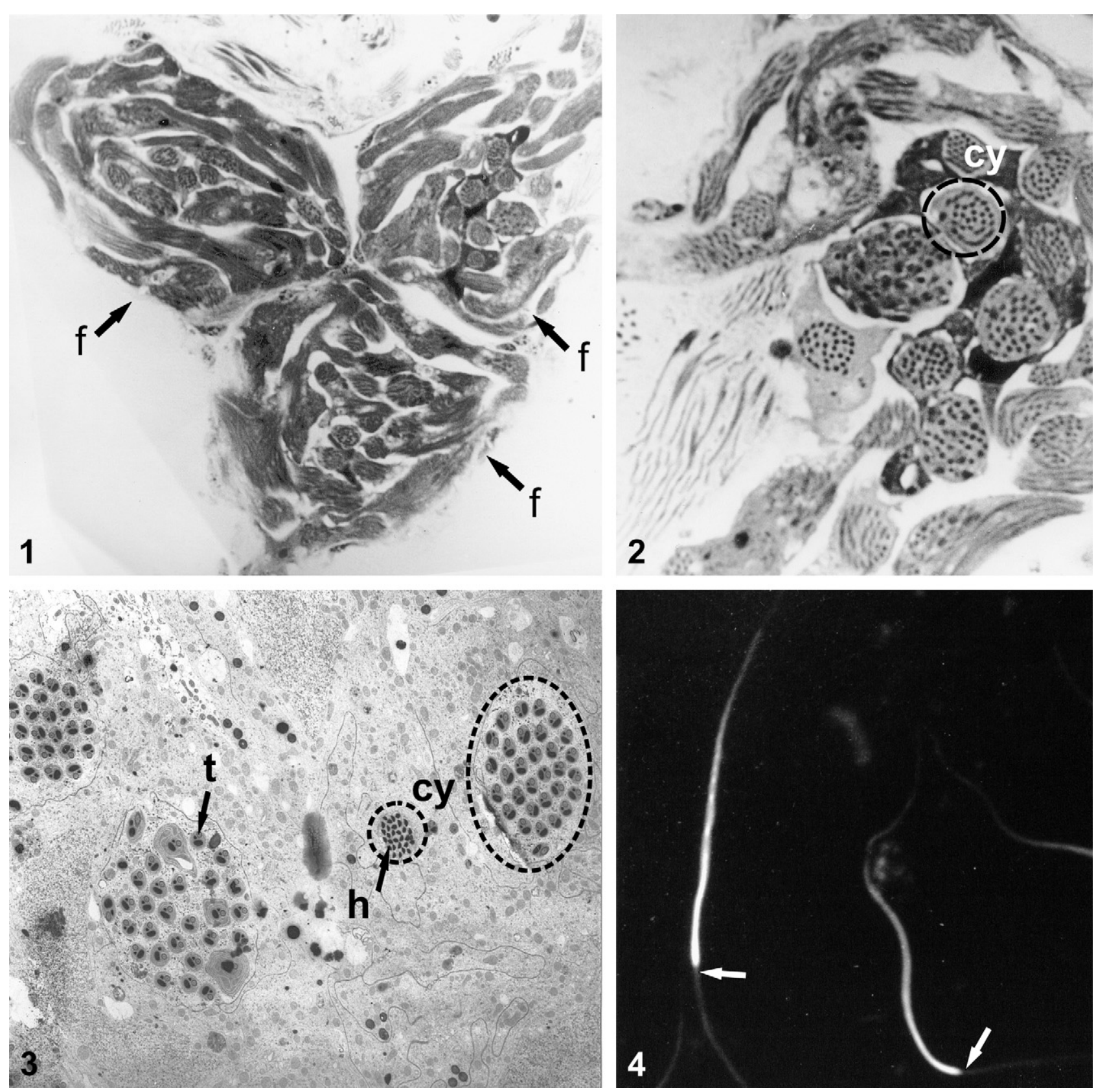

Plate 1. Figs. 1-3. Light and electron microscopy of testis of M. arlei. See the three testicular follicles (f) and the cysts (cy) containing up to 36 sperm. Compare the diameter of cysts sectioned at (h) head and (t) tail levels. Scale bar: (1) $11.6 \mu \mathrm{m}$; (2) $5 \mu \mathrm{m}$; (3) $1.7 \mu \mathrm{m}$. Fig. 4. DAPI of nuclei of M. nigrophthalmus. The arrow indicate the limit of the head and tail of sperm. Scale bar: (4) $3.8 \mu \mathrm{m}$.

\section{Results}

\subsection{Morphology of male reproductive system and spermatozoa}

The male reproductive system of $M$. arlei and M. nigrophthalmus is made up of a pair of testicles connected to two vas deferens, partially modified into seminal vesicles, and by a pair of accessory glands that open onto the ejaculatory duct. Each testicle consists of three follicles or testicular tubules internally divided into cysts where cystic cells surround the germ cells, all of which are at the same stage of spermatic development (Figs. 1-3). In the testis, the spermatids are arranged with a maximum number of 36 in each cyst (Figs. 2, 3).

Plate 2. Electron microscopy of the acrosomal region in the testis of M. arlei $(5,8)$ and the seminal vesicle of M. nigrophthalmus (6-7, 9-10). Figs. 5-7. Transverse and longitudinal sections of the acrosome (a) showing the paracrystalline organization. The arrowheads indicate the lateral projections and arrows the manchette microtubules. (n) Nuclear anterior tip. Scale bar: (5) $0.08 \mu \mathrm{m}$; (6) $0.13 \mu \mathrm{m}$; (7) $0.1 \mu \mathrm{m}$. Figs. 8-10. Transverse and longitudinal sections at the middle of the head region. Note the nuclear (n) projections coiling around the paracrystalline core of acrosome (a). Scale bar: (8) $0.08 \mu \mathrm{m}$; (9) $0.23 \mu \mathrm{m}$; (10) $0.06 \mu \mathrm{m}$. 


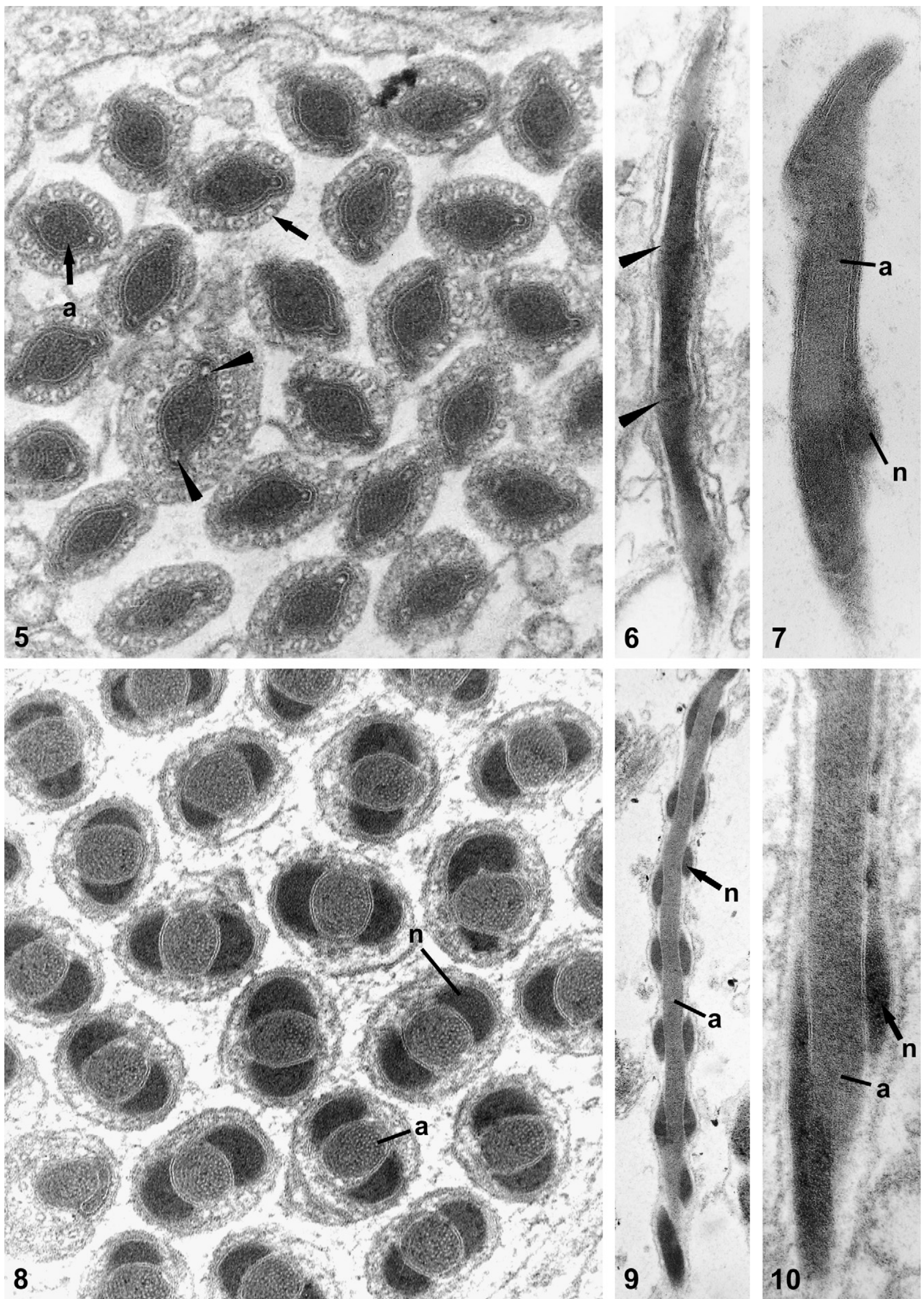



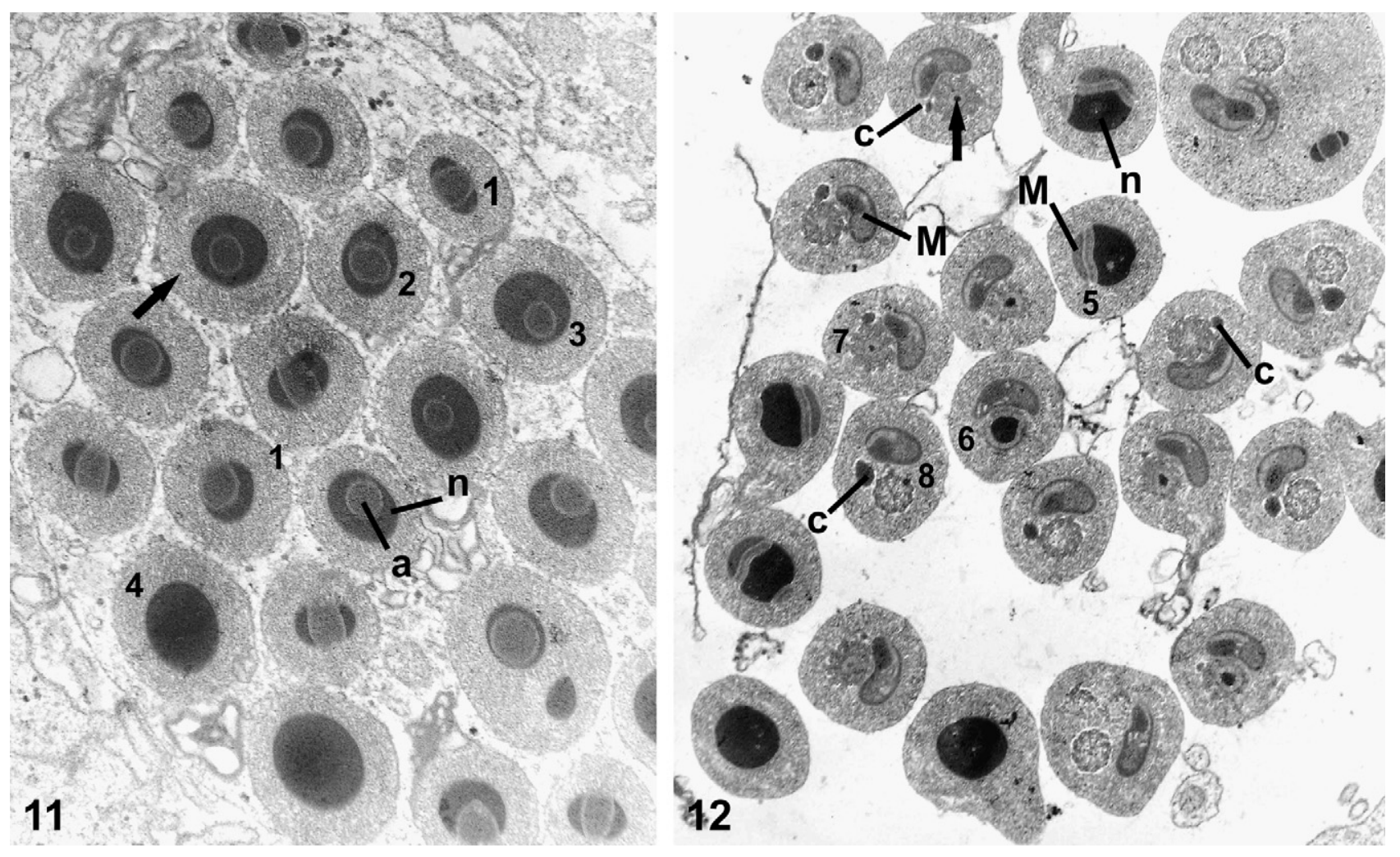

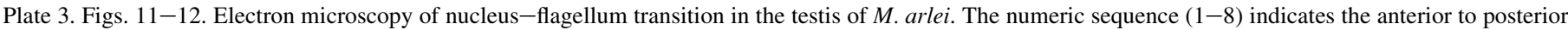

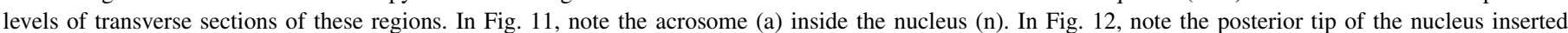

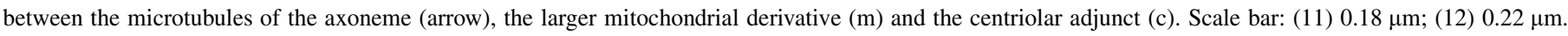

In the seminal vesicle, the spermatozoa are randomly dispersed.

The spermatozoa of these wasps are thin and extended, measuring about $813 \mu \mathrm{m}$ in length in $M$. arlei. In the spermatozoa of $M$. nigrophthalmus prepared by DAPI methodology, the nucleus is about $29 \mu \mathrm{m}$ in length (Fig. 4), the same as measured in spermatozoa of $M$. arlei. The spermatozoa appear wavy along their entire length. They can be divided into two regions: the head, formed by an acrosome and a nucleus and the tail, or flagellum, consisting of two mitochondrial derivatives, a centriolar adjunct, an axoneme and two accessory bodies.

The head is helically twisted and shows a very unusual morphological arrangement. The acrosome is very long and is basically made up of a paracrystalline structure. In anterior transverse sections, it is oval with two lateral projections at its largest diameter (Fig. 5). In longitudinal sections, these projections appear coiled around the paracrystalline structure. (Figs. $6,7)$. Transverse sections of the central head region show a circular acrosome, inserted into the nucleus that is observed lateral to the paracrystalline structure (Fig. 8). In longitudinal sections, the nucleus appears coiled around the paracrystalline structure, similarly to the acrosomal projection, although the nuclear spiral is wider than the acrosomic projections (Figs. 7, 9-10). In this region, the acrosome represents about one third to one half of the total area of the spermatozoan's cross section (Fig. 8). The subsequent portion of the head appears round in transverse sections (Figs. 11, 12), and the nucleus is penetrated by the acrosome until shortly above the flagellar insertion (see number sequence in Figs. 11, 12). Here the acrosome continues to be circular and paracrystalline but it becomes narrower and is dislocated toward the nuclear periphery (Fig. 11). The nucleus has an inverted cone-shape at its posterior end and projects into the centriole (Fig. 12). When treated with E-PTA, the nucleus, as observed in transverse sections, is completely negative whereas the acrosome varies from very negative to slightly positive (Fig. 21). The axoneme reveals the typical $9+9+2$ microtubule pattern, where the nine single accessory microtubules are the most external, followed by nine doublets and a central pair (Fig. 17).

Plate 4. Electron microscopy of flagella in the testis and seminal vesicle of $M$. arlei $(13,15-19)$ and $M$. nigrophthalmus $(14,20)$. Figs. 13-17. Transverse sections of the flagellum. Note the centriolar adjunct (c) and its extremity (14). (x) Axoneme; (M and m) the larger and smaller mitochondrial derivatives, respectively; (p) paracrystalline material; (b) accessory bodies. The arrows indicate microtubules of the manchette and, in the flagellum, $(\mathrm{am}, \mathrm{dm}, \mathrm{cm})$ indicate the accessory, doublets and central microtubules, respectively. Scale bar: $(13,15) 0.1 \mu \mathrm{m}$; (14) $0.08 \mu \mathrm{m}$; (16) $0.06 \mu \mathrm{m}$; (17) $0.07 \mu \mathrm{m}$. Figs. 18-19. Longitudinal and tangential sections of flagellum showing the cristae regions (cr). The star indicates the paracrystalline material of the larger mitochondrial derivative. Scale bar: (18) $0.1 \mu \mathrm{m}$; (19) $0.12 \mu \mathrm{m}$. Fig. 20. The final portion of axoneme without mitochondrial derivatives. Scale bar: (20) $0.06 \mu \mathrm{m}$. 


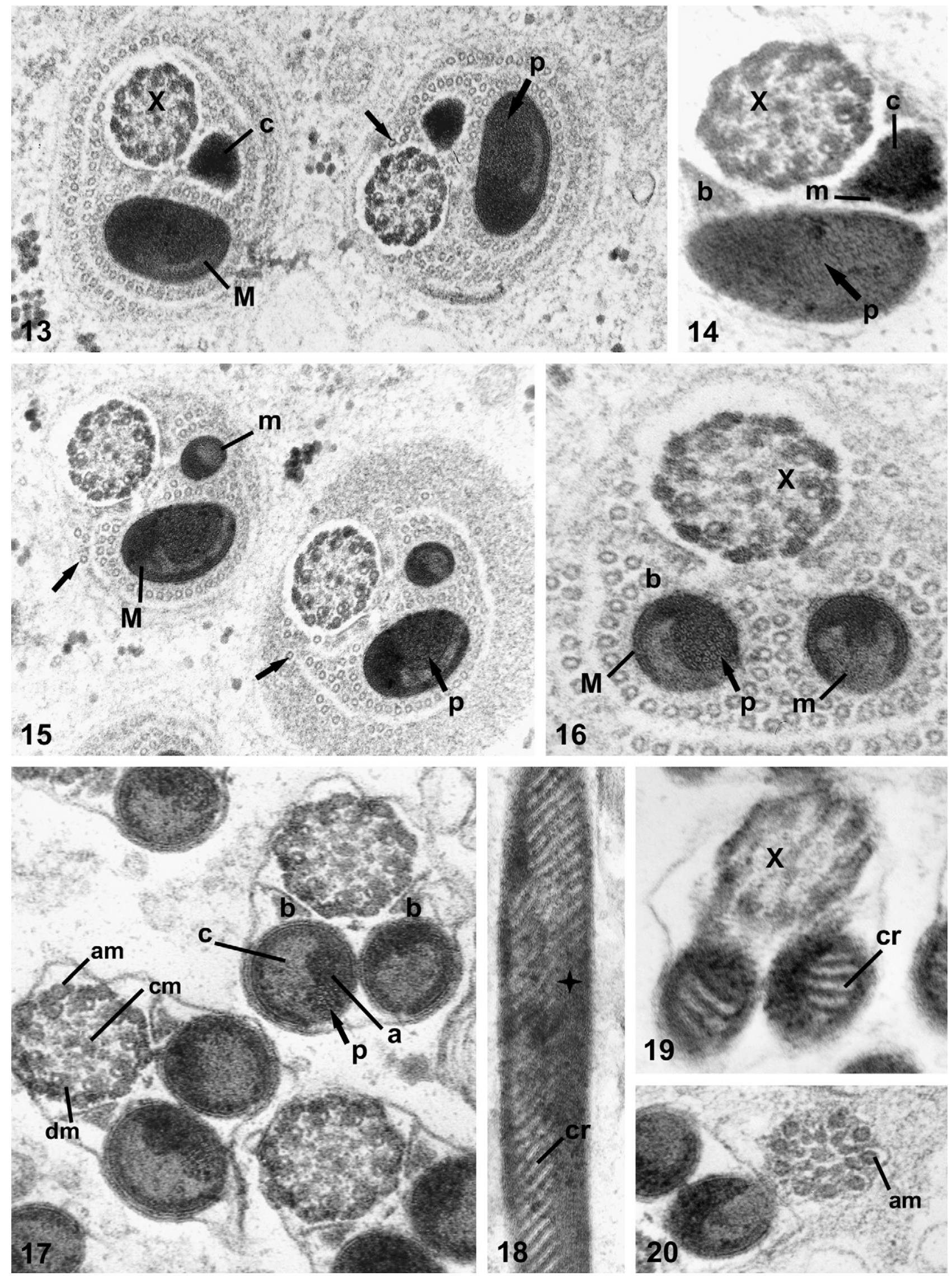


In the axoneme, only some intertubular material was E-PTA positive in transverse and longitudinal sections (Figs. 22-25). At the tip of the axoneme, the doublets and central pair terminate simultaneously and above the accessory ones (Figs. $20,24)$

In these wasps, the mitochondrial derivatives are divided into three regions (Fig. 17): (a) an electron dense region adjacent to the axoneme; (c) a clear mitochondrial cristae region, which occupies a large area of the mitochondrial derivatives; (p) the paracrystalline region, occurring only in the larger derivative (Figs. 13-17). Tangential sections of the cristae region show them to be perpendicular to the long axis of the derivatives and spaced at regular intervals (Figs. 18, 19). Only the cristae region stains positively with E-PTA (Fig. 25).

The mitochondrial derivatives are asymmetric in length and approximately symmetric in cross section (Figs. 15-17). The larger mitochondrial derivative is placed lateral to the nuclear projection ( $\mathrm{M}$ and $\mathrm{n}$, respectively, Fig. 12) while the smaller derivative begins adjacent to the posterior tip of the centriolar adjunct (Figs. 14, 15). At the initial portion of flagellum, the larger mitochondrial derivative is ellipsoidal in cross section (Figs. 13-15), and becomes circular after the insertion of the smaller derivative (Figs. 16, 17), which has a circular cross section (Figs. 12-17). The differences of their diameters are evident at their initial portion (compare Figs. 15 and 16), but along their major length they are similar (Figs. 16, 17, 19). The centriolar adjunct begins at the base of the nucleus and extends to the anterior tip of the smaller mitochondrial derivative (an asymmetric arrangement; Figs. 12-14). The adjunct is very long and remains parallel to the other flagellar organelles (Figs. 12-14). Transverse sections of the centriolar adjunct reveal its approximately triangular shape. Its cross section does not exceed the diameter of the mitochondrial derivative at its side (Fig. 13). This structure is E-PTA negative (Fig. 21).

The accessory bodies are approximately triangular in cross section. They are located exclusively between the axoneme and the mitochondrial derivatives and, therefore, are not seen accompanying the centriolar adjunct (b, Figs. 14, 16, 17). They are not detected with the E-PTA method.

\subsection{Phylogenetic evaluations}

The cladogram proposed in this work summarizes the relationships among Apoidea clades and Vespidae (Fig. 26). The characters inserted in this cladogram were obtained from sperm morphology (Table 1) and cytochemical data (Table 2). The character states considered are not polarized, so they do not necessarily represent a transformation series.

\section{Discussion}

The anatomy of the male reproductive system of Microstig$m u s$ is similar to that described for other Hymenoptera. The general morphology has been maintained in the order, but the number of testicular follicles varies considerably among minor groups, without obvious phylogenetic indication: in the Aculeata, the occurrence of three testicular follicles, as in Microstigmus, was still reported in other sphecid wasps of the subgenus Trypoxylon (Trypargilum) (Moreira et al., 2005a) as well as for some bee families (e.g. Andrenidae, Halictidae, some Megachilidae, Apidae sensu stricto Meliponini) (Ferreira et al., 2004; Araújo et al., 2005a) and in Vespidae (Brito et al., 2005; Moreira et al., 2005b). However, in other bees, as in Mellitidae, some Megachilidae and Apidae sensu stricto, with the exception of Apis mellifera with about 250 follicles (Chapman, 1998), each testicle presents four follicles (Roig-Alsina and Michener, 1993; Ferreira et al., 2004). In Formicidae, this number may vary from 1 to 25 (Forbes, 1958; Forbes and Do-Van-Quy, 1965; Beck, 1972; Palomeque et al., 1990; Wheeler and Krutzsch, 1992).

In the testicular follicles, the organization in cysts is also a common feature for species of Hymenoptera. However, the number of sperm contained in each cyst varies in accordance to the number of mitotic events and the viability of the spermatids in initial spermatogenesis. In the Apoidea, the number of sperm/cyst appears suggestive of an evolutionary event (Fig. 26). In Vespidae, considered here as an outgroup, the testicular follicle presents up to 128 spermatozoa (Brito et al., 2005). In the Sphecidae sensu stricto the number of sperm/ cyst is also 128 (Sceliphron fistularium) (Zama et al., 2005b). However, in Isodontia fuscipennis this number is reduced to only 32 sperm/cyst (personal observation), which could be an autapomorphy of this genus. Within Crabronidae, both the Crabroninae (Trypoxylon spp.) (personal observation) and Pemphredoninae (Microstigmus) present 64 sperm/cyst, which probably represents an apomorphy for this family. In Apidae sensu stricto some groups maintain the initial 128 sperm/cyst, however, in others, this number is also reduced up to $64 \mathrm{sperm} / \mathrm{cyst}$, because during spermatogenesis, at least half of the spermatids are unviable cells (Conte et al., 2005). Thus, the presence of 64 sperm/cyst in Crabronidae and Apidae sensu stricto is an independent event (homoplastic).

The structure of Hymenoptera sperm varies only in two aspects: (1) the morphometric data (e.g. total length, nuclear or flagellar measurements) and (2) the linear or twisted sperm cells (Fig. 26). The sperm length of M. arlei $(813 \mu \mathrm{m})$ is exceptionally long for the Aculeata. In Vespidae it varies from 13 to $577 \mu \mathrm{m}$ (Quicke et al., 1992; Mancini et al., 2006) while in Apoidea, these measurements vary between $80 \mu \mathrm{m}$ and $450 \mu \mathrm{m}$ for sphecids (Quicke et al., 1992; Zama et al., 2005b) and bees (e.g. Baer et al., 2003; Zama et al., 2004; Báo et al., 2004; Fiorillo et al., 2005a,b), except for Euglossini with 750 to $1.500 \mu \mathrm{m}$ in length (Zama et al., 2005a). Probably, the occurrence of a long sperm in Microstigmus and in Euglossini is not related and represents an apomorphic condition in both cases.

The twisted sperm was considered a characteristic of the parasitic wasps (Wilkes and Lee, 1965; Quicke et al., 1992; Lino-Neto et al., 1999, 2000a; Lino-Neto and Dolder, 2001b) and its occurrence in Symphyta and Aculeata has not yet been reported. Thus, the occurrence of twisted sperm in Microstigmus and in the Crabroninae, Trypoxylon spp. (personal observation), suggests that this characteristic is a reverse event in Aculeata, apomorphic for the Crabronidae. 


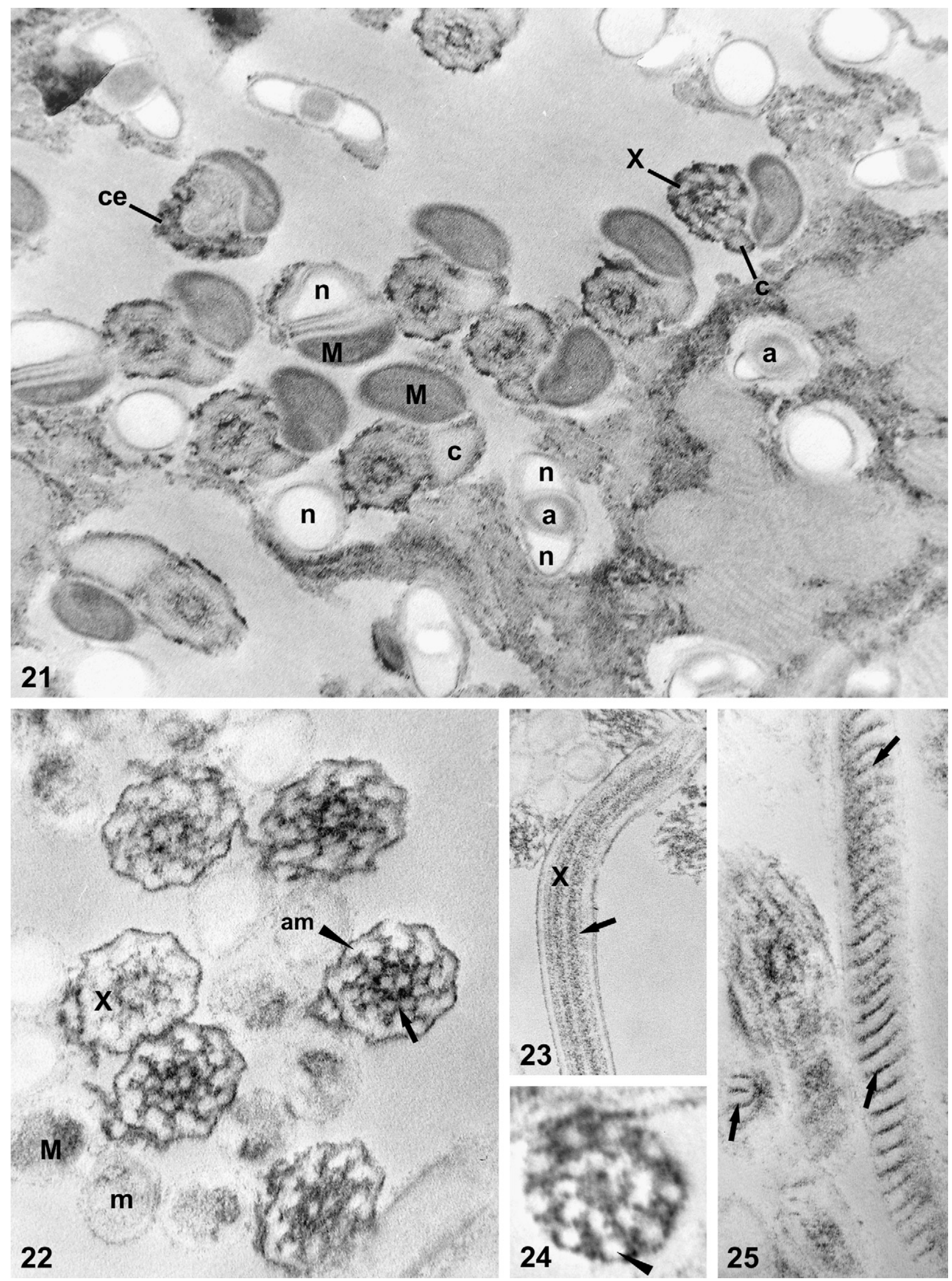

Plate 5. Figs. 21-25. Transverse (21-22, 24), longitudinal (23) and tangential (25) sections of testicular spermatozoa of M. nigrophthalmus treated by E-PTA methodology. Fig. 21-24: the nucleus (n) and the centriolar adjunct (c) are markedly negative while the acrosome (a) is slightly positive. Note the centriole (ce) and axoneme (x) where only the intertubular material (arrow) is positive, while the microtubules (arrowhead) are negative. (M and $\mathrm{m}$ ) mitochondrial derivatives. Fig. 25: only the cristae regions (arrows) are positive in the mitochondrial derivatives. Scale bar: $(21,23) 0.13 \mu \mathrm{m} ;(22,24-25) 0.06 \mu \mathrm{m}$. 


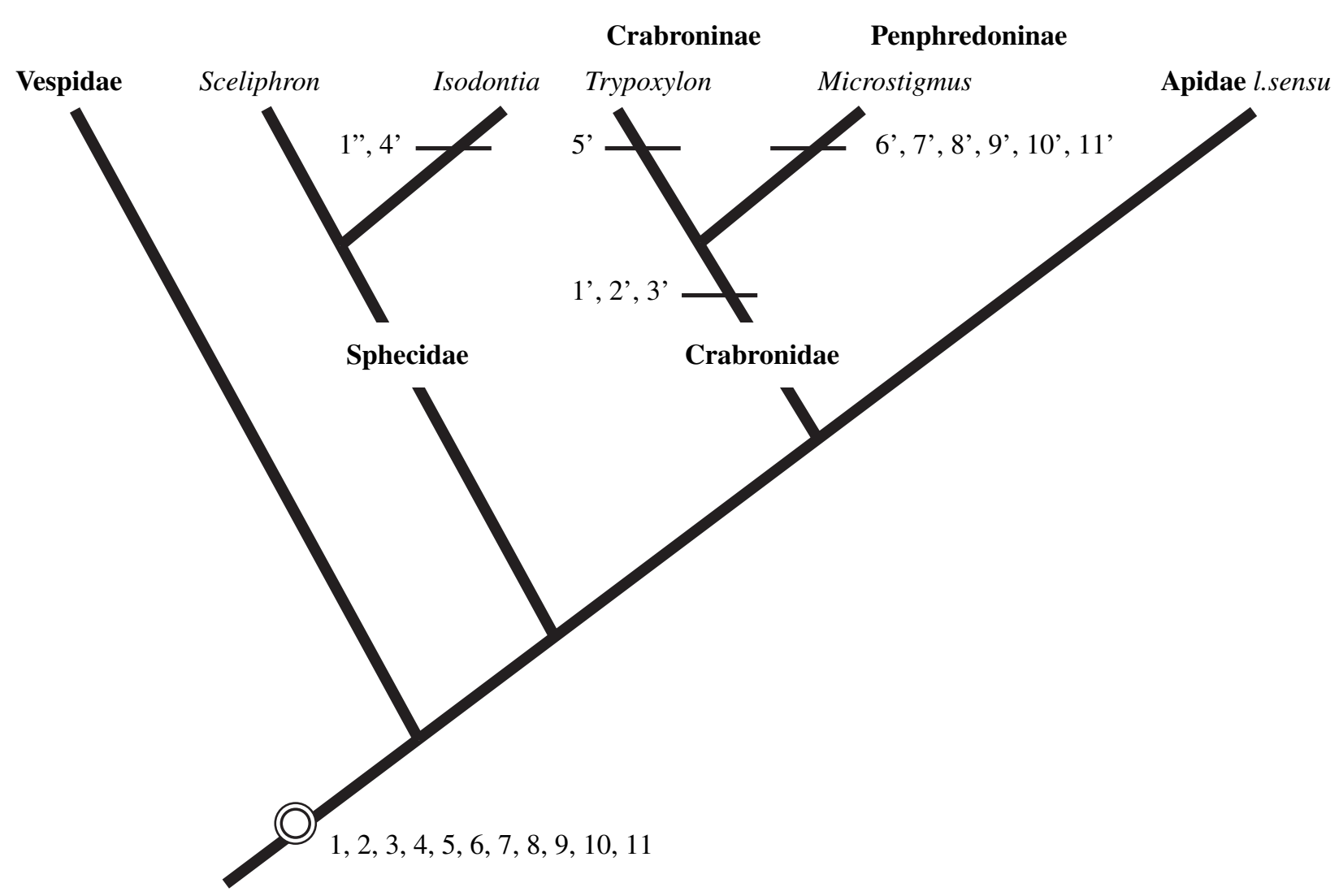

Plate 6. Fig. 26. Cladogram for Apoidea families (Sphecidae, Crabronidae and Apidae) and Vespidae modified from Alexander (1992) and Melo (1999, 2005, personal communication), with spermatozoal characters (Table 1).

The spermatozoa of Microstigmus have many ultrastructural characteristics in common with the majority of the Hymenoptera, for example: an elongated spermatozoon, the axoneme formed by $9+9+2$ microtubules, the presence of two mitochondrial derivatives, two accessory bodies and one centriolar adjunct. However, both M. arlei and M. nigrophthalmus present also some peculiarities that we recognize as autapomorphies (see $6^{\prime}$ to $11^{\prime}$ in the Fig. 26).

The morphology of the acrosome and nucleus observed in $M$. arlei and M. nigrophthalmus has not been previously described in Hymenoptera. The characters based on these structures are the most consistent autapomorphies for Microstigmus $\left(7^{\prime}, 8^{\prime}\right.$ and $9^{\prime}$, Fig. 26).

The paracrystalline structure of the Microstigmus acrosome probably represents the perforatorium already known for Hymenoptera. However, the interpretation of the lateral projection along the perforatorium as an acrosomal vesicle is not clear, in spite of the granular content that is occasionally found (arrowheads, Fig. 7). The acrosome, basically made up of a paracrystalline material, has been described for the symphytan Xyela julii (Newman and Quicke, 1999a). According to Newman and Quicke (1999a), in this Xyeloidea, the acrosome has a distinct paracrystalline core with a ridge that runs down one side of the acrosome. This ridge itself contains a particulate matter. It reveals granules surrounded by membranes resembling the multilayered coated complex that surrounds the acrosome itself. The acrosome loses the ridge at its posterior end, when it contacts the nucleus and may even be partially enclosed by it. This nuclear insertion is displaced to one side (asymmetric) as we also observed in Microstigmus. Despite these exceptions, the acrosome in Hymenoptera is made up of an acrosomal vesicle and a perforatorium (bilayered pattern) (Cruz-Höfling et al., 1970; Wheeler et al., 1990; Quicke et al., 1992; Newman and Quicke, 1999a; Lino-Neto and Dolder, 2001a, 2002; Zama et al., 2001, 2004, 2005a,c; Báo et al., 2004; Araújo et al., 2005b; Badke et al., 2005; Fiorillo et al., 2005a,b; Mancini et al., 2006) or includes an additional third layer, an extracellular sheath, which covers all the acrosomal vesicle and part of the nucleus (Quicke et al., 1992; Newman and Quicke, 1998, 1999b; LinoNeto et al., 1999, 2000a; Lino-Neto and Dolder, 2001a). As a rule, the perforatorium is dense and compact, but in some bees (Báo et al., 2004; Fiorillo et al., 2005a; Zama et al., 2005b) and in the Vespidae Agelaia vicina (Mancini et al., 2006), it appears slightly paracrystalline.

The anterior nuclear portion penetrated by the acrosome for most of its length is unprecedented for Hymenoptera. The nuclear base, penetrating into the axonemal insertion (at the centriolar level) is uncommon, but very similar to the arrangement known for the bees A. mellifera (Lino-Neto et al., 2000b), Xylocopa frontalis (Fiorillo et al., 2005b) and for the Vespidae A. vicina (Mancini et al., 2006). For the other Apoidea, the nuclear base finishes above the axonemal implantation (Zama et al., 2001, 2004, 2005a,b; Báo et al., 2004; Araújo et al., 
Table 2

A comparative analysis of E-PTA methodology in Hymenoptera

\begin{tabular}{|c|c|c|c|c|c|c|c|c|}
\hline \multirow[t]{2}{*}{ Group } & \multicolumn{7}{|l|}{ Structures } & \multirow[t]{2}{*}{ Reference } \\
\hline & Acrosomal vesicle & Perforatorium & Nucleus & $\begin{array}{l}\text { Centriolar } \\
\text { adjunct }\end{array}$ & $\begin{array}{l}\text { Mitochondrial } \\
\text { derivatives }\end{array}$ & Axoneme & Accessory bodies & \\
\hline \multicolumn{9}{|l|}{ Aculeate (Apoidea) } \\
\hline \multicolumn{9}{|l|}{ Crabronidae } \\
\hline Pemphredoninae & $?$ & $\begin{array}{l}\text { E-PTA Negative } \\
\text { to slightly } \\
\text { positive }\end{array}$ & E-PTA Negative & E-PTA Negative & $\begin{array}{l}a \text { and } p \text { are E-PTA } \\
\text { negative and cristae } \\
\text { (c) is E-PTA positive }\end{array}$ & $\begin{array}{l}\text { All microtubules are } \\
\text { E-PTA negative, } \\
\text { intertubular } \\
\text { material is E-PTA positive }\end{array}$ & E-PTA Negative & Present work \\
\hline Sphecidae & E-PTA Positive & $\begin{array}{l}\text { E-PTA Negative } \\
\text { with a positive } \\
\text { anterior tip }\end{array}$ & E-PTA Negative & E-PTA Negative & $\begin{array}{l}p \text { is E-PTA positive, } \\
a, b \text { and } c \text { are E-PTA } \\
\text { negative }\end{array}$ & $\begin{array}{l}A M \text { are E-PTA positive. } D M, \\
C M \text { and intertubular } \\
\text { material are E-PTA negative }\end{array}$ & $\begin{array}{l}\text { Slightly E-PTA } \\
\text { positive }\end{array}$ & Zama et al. (2005b) \\
\hline \multicolumn{9}{|l|}{ Apidae } \\
\hline Apini & $?$ & $?$ & $?$ & E-PTA Positive & $\begin{array}{l}b \text { is E-PTA positive, } a \\
p \text { and } c \text { are E-PTA } \\
\text { negative }\end{array}$ & $\begin{array}{l}A M \text { are E-PTA positive. } D M, \\
C M \text { and intertubular } \\
\text { material are E-PTA negative }\end{array}$ & E-PTA Positive & Lino-Neto et al. (2000b) \\
\hline Meliponini & E-PTA Positive & E-PTA Positive & $\begin{array}{l}\text { E-PTA Negative } \\
\text { with a central } \\
\text { positive region }\end{array}$ & E-PTA Negative & $\begin{array}{l}p \text { is E-PTA positive, } a \\
b \text { and } c \text { are E-PTA } \\
\text { negative }\end{array}$ & $\begin{array}{l}A M \text { are E-PTA positive. } D M, \\
C M \text { and intertubular } \\
\text { material are E-PTA negative }\end{array}$ & E-PTA Negative & $\begin{array}{l}\text { Zama (2003), Zama } \\
\text { et al. }(2001,2004)\end{array}$ \\
\hline Euglossini & E-PTA Positive & E-PTA Negative & $\begin{array}{l}\text { E-PTA Negative } \\
\text { with a central } \\
\text { positive region }\end{array}$ & E-PTA Negative & $\begin{array}{l}p \text { is slightly E-PTA } \\
\text { positive, } a, b \text { and } \\
c \text { are E-PTA negative }\end{array}$ & $\begin{array}{l}A M \text { and some intertubular } \\
\text { material are E-PTA } \\
\text { positive. } D M \text { and } C M \text { are } \\
\text { E-PTA negative }\end{array}$ & E-PTA Negative & $\begin{array}{l}\text { Zama (2003), Zama } \\
\text { et al. (2005a) }\end{array}$ \\
\hline Bombini & E-PTA Positive & E-PTA Negative & $\begin{array}{l}\text { E-PTA Negative } \\
\text { with a central } \\
\text { positive region }\end{array}$ & E-PTA Positive & $\begin{array}{l}b \text { is E-PTA positive, } \\
a, p \text { and } c \text { are } \\
\text { E-PTA negative }\end{array}$ & $\begin{array}{l}A M, C M \text { and intertubular } \\
\text { material are E-PTA } \\
\text { positive. } D M \text { is E-PTA negative }\end{array}$ & E-PTA Positive & Zama (2003) \\
\hline \multicolumn{9}{|l|}{ Parasitic wasps } \\
\hline Eurytomidae & $\begin{array}{l}\text { Acrosomal vesicle } \\
\text { and filaments are } \\
\text { E-PTA negative }\end{array}$ & $?$ & E-PTA Negative & E-PTA Negative & $\begin{array}{l}\text { E-PTA Slightly } \\
\text { positive }\end{array}$ & E-PTA Positive & $?$ & Lino-Neto et al. (1999) \\
\hline Trichogrammatidae & $\begin{array}{l}\text { Acrosomal vesicle } \\
\text { is E-PTA negative. } \\
\text { Filaments are E-PTA } \\
\text { positive }\end{array}$ & $?$ & E-PTA Negative & E-PTA Negative & $\begin{array}{l}\text { Slightly E-PTA } \\
\text { positive }\end{array}$ & $\begin{array}{l}\text { E-PTA Negative with E-PTA } \\
\text { positive material } \\
\text { coating the axoneme }\end{array}$ & $?$ & Lino-Neto et al. (2000a) \\
\hline
\end{tabular}

The letters $a, b, c$ and $p$ indicate the mitochondrial regions observed in transverse section. The abbreviations $A M, D M$ and $C M$ refer to accessory, doublets and central microtubules. 
2005b; Badke et al., 2005; Fiorillo et al., 2005a). This peculiar relation between perforatorium and nucleus challenges the unique apomorphic characteristic suggested by Jamieson et al. (1999) for Hymenoptera in relation to the Holometabola. This characteristic is reported as follows: "the perforatorium is attached to the anterior tip of the nucleus, where it is inserted in a short cavity" (Jamieson et al., 1999), as occurs in all Aculeata (Lino-Neto and Dolder, 2002; Zama et al., 2001, 2004, 2005a,c; Báo et al., 2004; Fiorillo et al., 2005a,b; Mancini et al., 2006).

The centriolar adjunct located between the nucleus and only one mitochondrial derivative (asymmetric pattern) observed in Microstigmus seems to be a synapomorphic character in Hymenoptera, because it occurs in Symphyta (except Siricoidea), a taxon that is considered to be the basal highergroup (Newman and Quicke, 1999a), as well as in some parasitic wasps (Newman and Quicke, 1998, 1999b), in Apoidea (Lino-Neto et al., 2000b; Zama, 2003; Zama et al., 2001, 2004, 2005a,c; Báo et al., 2004; Araújo et al., 2005b; Badke et al., 2005; Fiorillo et al., 2005a,b) and in Vespidae (Mancini et al., in press). However, in the symphytan Tremex sp. (Newman and Quicke, 1999a), in the parasitic wasps Chalcidoidea (Lino-Neto et al., 1999, 2000a; Lino-Neto and Dolder, 2001b), in the aculeatans Formicidae (Wheeler et al., 1990; Lino-Neto and Dolder, 2002) and Crabroninae (Trypoxylon spp.) (Zama et al., 2005b), the centriolar adjunct precedes both mitochondrial derivatives in a symmetric pattern. The occurrence of this pattern in Crabroninae probably represents a reverse event (5', Fig. 26). Also, in Scelionidae, another parasitic wasp, no centriolar adjunct was observed (Lino-Neto and Dolder, 2001a).

In Microstigmus, the mitochondrial derivatives are asymmetric in length, but approximately symmetric in diameter. The asymmetry in length and diameter of these structures is a characteristic shared by all Apoidea (e.g. Zama et al., 2001, 2004, 2005a,b,c; Báo et al., 2004; Fiorillo et al., 2005a,b) and Vespidae (Mancini et al., 2006), while symmetry has been previously reported for Formicidae (Wheeler et al., 1990; Lino-Neto et al., 2000b; Mancini et al., 2005). These patterns seem to be homoplastic, because large variations are found within the Hymenoptera: they are asymmetric in some Symphyta (Newman and Quicke, 1999a), Eucoilidae (Newman and Quicke, 1999b) and Megalyroidea (Newman and Quicke, 2000), while in Siricoidea (Symphyta) (Newman and Quicke, 1999a), Ichneumonoidea (Quicke et al., 1992) and Chalcidoidea (Lino-Neto et al., 1999, 2000a; Lino-Neto and Dolder, 2001b) they are symmetric. In addition, in the parasitic wasps Scelionidae, only one mitochondrial derivative was observed (Lino-Neto and Dolder, 2001a).

Furthermore, the mitochondrial regions described here are somewhat similar to the ones described for Apoidea (LinoNeto et al., 2000b; Zama et al., 2001, 2004, 2005a,b,c; Araújo et al., 2005b; Badke et al., 2005; Fiorillo et al., 2005a,b) and Vespidae (Mancini et al., 2006). Nevertheless, one unusual aspect that can distinguish I. fuscipennis (Sphecidae sensu stricto) from the other Apoidea is the presence of paracrystalline material in both mitochondrial derivatives (4', Fig. 26).
The microtubular arrangement pattern is largely conserved in Hymenoptera, however, the sequence of their cutoff in the final axonemal portion differs between the major groups of Apocrita. In all Aculeata, the central microtubules and the nine doublets terminate first, followed by the accessory microtubules (Lino-Neto et al., 2000b; Zama et al., 2001, 2004, 2005a,b; Báo et al., 2004; Araújo et al., 2005b; Fiorillo et al., 2005a; Mancini et al., 2006) or, in ants, they all terminate approximately together (Wheeler et al., 1990; Lino-Neto and Dolder, 2002). In the Parasitica the nine doublets are the last microtubules to be lost at the flagellum tip (Lino-Neto et al., 1999, 2000a; Lino-Neto and Dolder, 2001b). So, these character conditions seem to corroborate the division of the major groups.

E-PTA treatment is a cytochemical ultrastructural method that enhances the presence of basic constitutive proteins. This method has been useful to differentiate the sperm of the corbiculated tribes of bees (Zama, 2003). The method also proved to be important in the ultrastructural description of $S$. fistularium (Zama et al., 2005c) and some parasitic wasp spermatozoa (Lino-Neto et al., 1999, 2000a) (see Table 2). Here, the most obvious difference obtained with this methodology is the different staining patterns of the axoneme among Crabroninae, Sphecidae sensu stricto and Apidae sensu lato (Table 2). In the Crabroninae, both in Trypoxylon spp. (personal observation) and in Microstigmus, the perimicrotubular proteins are positive, while all the microtubules are negative. In the other Apoidea, at least one kind of microtubules, accessory, doublets or central pair is positively stained, and sometimes, the microtubular material is also positive.

The very unusual morphology of the head region encountered in these two species belonging to the same genus is an unexpected alteration that sets them apart from other sphecids, suggesting that this group should be studied in greater detail.

Recent research has accumulated a great deal of information on the ultrastructure of insect sperm. This growing data set will open new avenues of research in both phylogenetic reconstruction and comparative analysis.

\section{Acknowledgments}

We would like to express our gratitude to Prof. Dr. Gabriel Melo (Universidade Federal do Paraná - UFPR) and to Prof. Dr. André Victor Lucci (UNICAMP) for the careful review of the phylogenetic aspects of this study. This work was supported by Brazilian agencies CNPq (Proc. 150296/2003-7), FAPESP (Proc. 2003/09354-8) and FAEPEX/UNICAMP (Proc. 1539/04).

\section{References}

Alexander, B.A., 1992. An exploratory analysis of cladistic relationships within the superfamily Apoidea, with special reference to Sphecid wasps (Hymenoptera). Journal of Hymenoptera Research 1 (1), 25-61.

Araújo, V.A., Zama, U., Neves, C.A., Dolder, H., Lino-Neto, J., 2005a. Ultrastructural, histological and histochemical characteristics of the epithelial wall of the seminal vesicle of mature Scaptotrigona xanthotricha Moure 
males (Hymenoptera, Apidae, Meliponini). Brazilian Journal of Morphological Sciences 22 (4), 193-201.

Araújo, V.A., Zama, U., Dolder, H., Lino-Neto, J., 2005b. Morphology and ultrastructure of the spermatozoa of Scaptotrigona xanthotricha Moure (Hymenoptera, Apidae, Meliponini). Brazilian Journal of Morphological Sciences 22 (3), 137-141.

Asís, J.D., 2003. Nesting biology of Microstigmus thripoctenus Richards, with a study on nest recognition (Hymenoptera: Crabronidae). Journal of Insect Behavior 16 (1), 49-65.

Badke, J.P., Banin, T.M., Scorza, L.C.T., Zama, U., Lino-Neto, J., Dolder, H., 2005. Ultrastructure of spermatozoa in Partamona helleri Friese (1900) (Hymenoptera, Apidae, Meliponini). Brazilian Journal of Morphological Sciences 22 (Suppl.), 64-65.

Baer, B., Schmid-Hempel, P., Hoeg, J.T., Boomsma, J.J., 2003. Sperm length, sperm storage and mating system characteristics in bumblebees. Insectes Sociaux 50, 101-108.

Báo, S.N., Gonçalves Simões, D., Lino-Neto, J., 2004. Sperm ultrastructure of the bees Exomalopsis(Exomalopsis)auropilosa Spinola 1853 and Paratetrapedia(Lophopedia) sp. Michener \& Moures 1957 (Hymenoptera, Apidae, Apinae). Journal of Submicroscopic Cytology and Pathology 36 (1), 23-28.

Beck, V.H., 1972. Vergleichende histologische untersuchungen an Polyergus rufescens und Raptiformica sanguinea. Insectes Sociaux 19, 301-342.

Bohart, R.M., Menke, A.S., 1976. Sphecidae Wasp of the World. A Generic Revision. University of California Press, Berkeley.

Brito, P., Moreira, J., Lino-Neto, J., 2005. Morphology of male reproductive system and sperm of Mischocyttarus sp. (Hymenoptera: Vespidae: Polistinae). Brazilian Journal of Morphological Sciences 22 (Suppl.), 175-176.

Chapman, R.F., 1998. The Insects: Structure and Function, fourth ed. Cambridge Univ. Press, Cambrige.

Conte, M., Lino-Neto, J., Dolder, H., 2005. Spermatogenesis of Melipona quadrifasciata anthidioides (Hymenoptera: Apidae): fate of the atypical spermatids. Caryologia 58 (2), 183-188.

Cruz-Höfling, M.A., Cruz-Landim, C., Kitajima, E.W., 1970. The fine structure of spermatozoa from the honey bee. Anais da Academia Brasileira de Ciências 42, 69-78.

Ferreira, A., Abdalla, F.C., Kerr, W.E., Cruz-Landim, C., 2004. Systematics, morphology and physiology. Comparative anatomy of the male reproductive internal organs of 51 species of bees. Neotropical Entomology 33, 569-576.

Fiorillo, B.S., Coelho, A.A.M., Lino-Neto, J., Báo, S.N., 2005a. Structure and ultrastructure of the spermatozoa of Halictidae (Hymenoptera, Apoidea). Journal of Submicroscopic Cytology and Pathology 37 (1), 75-81.

Fiorillo, B., Lino-Neto, J., Báo, S.N., 2005b. Ultrastructural characterization of the spermatozoon of Xylocopa frontalis (Hymenoptera: Anthophoridae). Brazilian Journal of Morphological Sciences 22 (Suppl.), 60-61.

Forbes, J., 1958. The male reproductive system of the army ant, Eciton hamatum. In: Proceedings of 10th International Congress of Emtomology, 593596.

Forbes, J., Do-Van-Quy, D., 1965. The anatomy and histology of the male reproductive tract of the legionary ant Neivamyrmex harrisi. Journal of the New York Entomological Society 73, 95-111.

Jamieson, B.G.M., Dallai, R., Afzelius, B.A., 1999. Insects: Their Spermatozoa and Phylogeny. Scientific Publishers, Enfield, USA.

Lino-Neto, J., Báo, S.N., Dolder, H., 1999. Structure and ultrastructure of the spermatozoa of Bephratelloides pomorum (Fabricius) (Hymenoptera: Eurytomidae). International Journal of Insect Morphology and Embryology 28, $253-259$.

Lino-Neto, J., Báo, S.N., Dolder, H., 2000a. Structure and ultrastructure of the spermatozoa of Trichogramma pretiosum Riley and Trichogramma atopovirilia Oatman and Platner (Hymenoptera: Trichogrammatidae). Acta Zoologica (Stockholm) 81, 205-211.

Lino-Neto, J., Báo, S.N., Dolder, H., 2000b. Sperm ultrastructure of the honey bee (Apis mellifera) (L.) (Hymenoptera, Apidae) with emphasis on the nucleus-flagellum transition region. Tissue and Cell 32, 322-327.

Lino-Neto, J., Dolder, H., 2001a. Ultrastructural characteristics of the spermatozoa of Scelionidae (Hymenoptera; Platygastroidea) with phylogenetic considerations. Zoologica Scripta 30, 89-96.
Lino-Neto, J., Dolder, H., 2001b. Redescription of sperm structure and ultrastructure of Trichogramma dendrolimi (Hymenoptera: Chalcidoidea: Trichogrammatidae). Acta Zoologica (Stockholm) 82, 159-164.

Lino-Neto, J., Dolder, H., 2002. Sperm structure and ultrastructure of the fire ant Solenopsis invicta Bauren (Hymenoptera, Formicidae). Tissue and Cell 34, 124-128.

Mancini, K., Lino-Neto, J., Delabie, J., Dolder, H., 2005. The agregated sperm of army ants (Hymenoptera: Formicidae: Ecitoninae). Brazilian Journal of Morphological Sciences 22 (Suppl.), 54.

Mancini, K., Lino-Neto, J., Campos, L.A.O., Dolder, H., 2006. Sperm ultrastructure of the wasp Agelaia vicina (Hymenoptera: Vespidae). Insectes Sociaux 53, 333-338.

Matthews, R.W., 1968. Nesting biology of social wasp Microstigmus comes (Hymenoptera, Sphecidae, Penphredoninae). Psyche 75, 23-45.

Matthews, R.W., 1991. Evolutionary of social behavior in sphecid wasps. In: Ross, K.G., Matthews, R.W. (Eds.), The Social Biology of Wasps. Cornell Univ. Press, Ithaca, Comstock.

Matthews, R.W., Starr, C.K., 1984. Microstigmus comes wasps have a method of nest construction unique among social insects. Biotropica 16, $55-58$.

Melo, G.A.R., 1999. Phylogenetic relationships and classification of the major lineages of Apoidea (Hymenoptera), with emphasis on the cabronid wasps. In: University of Kansas Science Bulletin, 14, pp. 1-55.

Melo, G.A.R., 2000. Comportamento social em vespas da família Sphecidae (Hymenoptera, Sphecidae). In: Martins, R.L., Lewinsohn, T.M., Barbeitos, M.S. (Eds.), Ecologia e Comportamento de Insetos. Série Oecologia Brasiliensis, 85-130. Rio de Janeiro.

Moreira, P.A., Araújo, V.A., Zama, U., Lino-Neto, J., 2005a. Internal reproductive system in males of the subgenus Trypoxylon (Trypargilum) (Hymenoptera: Apoidea: Crabronidae). Brazilian Journal of Morphological Sciences 22 (Suppl.), 169-170.

Moreira, P.A., Araújo, V.A., Lino-Neto, J., 2005b. Morphology of male reproductive system of Polistes versicolor (Hymenoptera, Vespidae, Polistini). Brazilian Journal of Morphological Sciences 22 (Suppl.), 176-177.

Newman, T.M., Quicke, D.L.J., 1998. Sperm development in the imaginal testes of Aleiodes coxalis (Hymenoptera: Braconidae: Rogadinae). Journal of Hymenoptera Research 7, 25-37.

Newman, T.M., Quicke, D.L.J., 1999a. Ultrastructure of imaginal spermatozoa of sawflies (Hymenoptera: Symphyta). Journal of Hymenoptera Research $8,35-47$.

Newman, T.M., Quicke, D.L.J., 1999b. Ultrastructure of spermatozoa in Leptopilina (Hymenoptera: Cynipoidea: Eucoilidae). Journal of Hymenoptera Research 8, 197-203.

Newman, T.M., Quicke, D.L.J., 2000. Sperm development and ultrastructure of mature spermatozoa of Megalyra (Hymenoptera: Megalyroidea). Journal of Hymenoptera Research 9, 62-70.

Palomeque, T., Cano, M.A., Chica, E., Diaz de la Guardia, R., 1990. Spermatogenesis in Tapinoma nigerrimum (Hymenoptera, Formicidae). Cytobios 62, 71-80.

Quicke, D.L.J., Ingram, S.N., Baillie, H.S., Gaitens, P.V., 1992. Sperm structure and ultrastructure in the Hymenoptera (Insecta). Zoologica Scripta 21, 381-402.

Roig-Alsina, A., Michener, C.D., 1993. Studies of the phylogeny and classification of long-tong bees (Hymenoptera: Apoidea). University of Kansas Science Bulletin 55, 123-162.

Ross, K.G., Matthews, R.W., 1989. New evidence for eusociality in the Sphecidae wasp Microstigmus comes. Animal Behavior 38, 613-619.

Wheeler, D.E., Crichton, E.D., Krutzsch, P.H., 1990. Comparative ultrastructure of ant spermatozoa (Formicidae: Hymenoptera). Journal of Morphology 206, 343-350.

Wheeler, D.E., Krutzsch, P.H., 1992. Internal reproductive system in adult males of the genus Camponotus (Hymenoptera: Formicidae: Formicinae). Journal of Morphology 211, 307-317.

Wilkes, A., Lee, P.E., 1965. The ultrastructure of dimorphic spermatozoa in hymenoptera Dahlbominus fuscipennis (Zett.) (Eulophidae). Canadian Journal of Genetics and Cytology 7, 609-619.

Wilson, O.E., 1971. The Insect Societies. Belknap Press, Harvard, Cambridge. 
Zama, U.S., 2003. Estudo estrutural e ultraestrutural dos espermatozóides nas tribos Apini, Bombini, Euglossini e Meliponini (Hymenoptera: Apinae), com considerações filogenéticas. $\mathrm{PhD}$ thesis, State University of Campinas.

Zama, U., Lino-Neto, J., Dolder, H., 2001. Ultrastructure of spermatozoa in Plebeia (Plebeia)droryana Friese (Hymenoptera: Apidae: Meliponina). Journal of Hymenoptera Research 10, 261-270.

Zama, U., Lino-Neto, J., Dolder, H., 2004. Structure and ultrastructure of spermatozoa in Meliponini (stingless bees) (Hymenoptera: Apidae). Tissue and Cell 36, 29-41.

Zama, U., Lino-Neto, J., Melo, S.M., Campos, L.A.O., Dolder, H., 2005a. Ultrastructural characterization of spermatozoa in Euglossini bees (Hymenoptera: Apidae: Apinae). Insectes Sociaux 52 (2), 122-131.

Zama, U., Bottura, G., Lino-Neto, J., Dolder, H., Báo, S.N., 2005b. The nucleusflagellum transition in Trypoxylon (Trypargilum) subgenus, with emphasis on a singular centriolar adjunct (Hymenoptera: Apoidea: Crabronidae). Brazilian Journal of Morphological Sciences 22 (Suppl.), 56.

Zama, U., Brito, P., Lino-Neto, J., Campos, L.A.O., Dolder, H., Báo, S.N., 2005c. The sperm morphology of mud dauber Sceliphron fistularium Dahlbom (Hymenoptera: Apoidea: Sphecidae), as an indicative of bees relation. Journal of Submicroscopic Cytology and Pathology 37 (3-4), 91-99. 